\title{
Role of the embryo in crab terrestrialisation: an ontogenetic approach
}

\author{
Stefano Cannicci ${ }^{1, *}$, Riccardo Simoni ${ }^{1}$, Folco Giomi ${ }^{2}$ \\ ${ }^{1}$ Dipartimento di Biologia Evoluzionistica, Università degli Studi di Firenze, 50125 Florence, Italy \\ ${ }^{2}$ Alfred-Wegener-Institute for Polar and Marine Research, Department of Integrative Ecophysiology, 27570 Bremerhaven, Germany
}

\begin{abstract}
Strategies permitting amphibious brachyurans to successfully occupy land environments have long been studied, with a focus on both the adult-terrestrial and larval-water-dependent stages. However, the ontogenetic approach to terrestrial adaptations in crabs has not considered the strategies of embryos, even though natural selection should act on all stages of development. We review the state of the field of reproductive adaptations of terrestrial crabs through both an extensive meta-analysis, aiming at testing the current hypotheses suggesting evolutionary trends towards an increase in egg size and decrease in total egg clutch during the conquest of land, and the presentation of novel data on bimodal respiration of crab embryos. Published studies on the morphological characteristics of eggs and on the reproductive traits of 121 marine, freshwater and terrestrial species of brachyurans could not confirm the currently hypothesized trends. Our meta-analysis confirms that the conquest of land by brachyurans implies strong selective pressures at all developmental levels, leading towards fundamental evolutionary steps, such as the air respiration of embryos. Our novel data on aquatic and aerial respiration in the embryos of an intertidal and a shallow subtidal species confirm recent data showing that early life stages of crabs are able to breathe in air, although they are apparently water dependent. An ontogenetic approach is needed to formulate new hypotheses regarding trends in terrestrial adaptations at all brachyuran life stages and to highlight other embryonic processes related to terrestrialisation, such as excretion, which is of the utmost importance in terrestrial adult crabs.
\end{abstract}

KEY WORDS: Terrestrial adaptations $\cdot$ Crab embryo $\cdot$ Respiration $\cdot$ Reproductive strategy $\cdot$ Maternal care $\cdot$ Developmental pathways $\cdot$ Marine-terrestrial ecotone $\cdot$ Bimodal respiration

Resale or republication not permitted without written consent of the publisher

\section{INTRODUCTION}

Strategies permitting brachyuran crabs to successfully occupy a variety of terrestrial and semi-terrestrial environments have long been studied (for reviews see Bliss 1968, Burggren \& McMahon 1988, Greenaway 1999). Previous research has demonstrated how the adult stages of terrestrial and semi-terrestrial crabs evolved integrated strategies, encompassing morphological (Hartnoll 1988, Vannini et al. 1997, Fratini et al. 2005), respiratory (Innes \& Taylor 1986, Farrelly \& Greenaway 1993, 1994, Morris 2002), excretory (Morris 2001, Weihrauch et al. 2004), ecological (Wolcott 1988) and behavioural adaptations (Warner 1967, Can- nicci et al. 1996, Vannini et al. 1997), to adjust to the relatively new environment. On the other hand, larval stages of the great majority of terrestrial brachyuran are still strongly dependent on either marine environments or freshwater habitats, often presenting no adaptations to cope with truly terrestrial conditions (Anger 1995). This generalised amphibious life-cycle strongly affects the life-history patterns of terrestrial and semi-terrestrial species, leading to critical consequences for their reproductive ecology (Wolcott 1988) and for the parental behaviour of reproducing females (Diesel 1992, Diesel \& Horst 1995). In contrast to the vast amount of data collected about the adaptive strategies used by the adult and larval stages of 
amphibious brachyurans to cope with the different environmental challenges, an ontogenetic approach has never been applied to eggs and embryos.

Charmantier \& Wolcott (2001) called for an ontogenetic approach to adaptive strategies in ecological and physiological studies, citing Bartholomew (1987) and Burggren (1992). These authors followed the simple rationale that natural selection acts on all stages of development and that ontogenetic strategies, defined as the adaptations of the different stages of development of diverse taxa, should be studied at all stages of development, including the egg and embryo. Research into the terrestrial adaptations of the eggs and embryos of amphibious crabs is both regrettably absent and, in our opinion, of extreme importance in understanding the evolutionary pathways leading to the conquest of land, for at least 2 reasons. First, there is a strong link, in crabs, between the mother and the embryos, and, secondly, embryos represent the link between the terrestrial adult stage and the waterdependent larval stage of most species (Anger 1995). Female crabs do, in fact, take care of their embryos until larval hatching, undertaking energy-costly parental care (see Fernandez \& Brante 2003 for a review). Carrying mothers and embryos form an ecological unit whose biology is shaped and often limited by the ecological requirements of the embryos. As a consequence, an ontogenetic approach, aimed at understanding the eco-physiological traits of embryos during their developmental stages, is needed to highlight the adaptive strategies of amphibious carrying mothers and the overall ecological needs of the species themselves.

Unfortunately, very little is known about the ontogenetic adaptations of embryos of terrestrial and semiterrestrial crabs, and the few hypotheses that have been formulated about embryonic adaptations actually only deal with the optimisation of egg size and egg clutch volume to cope with a low oxygen tension. The rationale behind these hypotheses is that, although it is difficult to ascertain if the interstices of the egg masses of terrestrial and intertidal crabs are occupied by water or air, problems of anoxia should arise in any case. Thus, a morphological adaptation to prevent low oxygen tension of the interstitial medium should be an increase of average egg size, since this trait could become adaptive, resulting in the enlargement of the interstices within the mass (Strathmann \& Chaffee 1984, Strathmann \& Hess 1999). Enlarged interstices, in fact, will both favour the fluxes of the respiratory medium and prevent their water-filling by capillarity, a critical issue for air-breathing embryos. This trend in egg size increase from marine to terrestrial crabs has been confirmed by Anger (1995), although the core of his review involved larval adaptations to retention strategies and not embryos. Another biological adaptation to anoxia within egg mass interstices was suggested by Hartnoll et al. (2007), who pointed out that terrestrial crabs may reduce the production of eggs at each spawning event, thus reducing clutch volume and, consequently, problems due to hypoxia at its centre. Both the above hypotheses tacitly imply that the embryonic phase of terrestrial and semi-terrestrial crabs remains strongly water dependent, with the need for a constant supply of water for metabolic processes such as respiration and excretion. The main aim of the present article is provide an overall review about the state of the field of reproductive adaptation of terrestrial crabs, by means of: (1) testing the suggested hypotheses on the characteristics of egg and egg clutch of terrestrial crabs, through a meta-analysis on a large dataset of egg characteristics of marine, freshwater and terrestrial crabs, and (2) suggesting a new interpretation of the existing information on the basis of novel data on the capability of crab embryos to breathe air.

\section{MATERIALS AND METHODS}

Meta-analyses on egg characteristics. We searched for research and review papers dealing with the reproductive output of crab species colonising any kind of environment. Papers presenting any sort of data related to the dimension and number of eggs, even if inferred from the total egg mass, have been included in our dataset. The response variables directly collected or inferred from the original papers were: (1) the average diameter (in $\mu \mathrm{m}$ ) of eggs produced, (2) their average number in a single clutch and (3) the total volume (in $\mathrm{mm}^{3}$ ) of the average egg mass volume. We found 38 papers on the egg production of crabs, which provided data on 121 species, since some papers were comparative studies on $>1$ species. To analyse the influence of adult habitat and larval development on the response variables, we divided the 121 selected species into distinct classes. Regarding adult habitat, we differentiated between marine species $(\mathrm{M})$, intertidal species (IT), terrestrial species from marine or intertidal ancestors $(\mathrm{T}(\mathrm{M})$ ), freshwater species $(\mathrm{F})$ and terrestrial species from freshwater ancestors $(T(F))$. From this particular analysis we excluded the Chinese mitten crab Eriocheir sinensis, since the adults of this species are truly freshwater dwellers, but the ovigerous females reach the sea for spawning and can be considered marine in this part of their lifecycles. E. sinensis was, however, included in the rest of the analyses, since it was possible to clearly define its larval development and its taxonomical status. For larval development we considered 3 categories: 
(1) species having larvae with full development in water environments (export strategy, E), (2) species that retain larvae with a shortened development cycle in particular habitats (retention strategy, R) and (3) species with direct development of larvae in the egg (direct development, D). To test for possible effects of phylogenetic relatedness on the response variables, the species were also grouped at the family level, in a third analysis. If the source papers did not mention biological (such as average carapace width; CW), ecological, or taxonomic characteristics, we searched for other source papers to complete the dataset.

Given the well-known relationship between female dimensions and egg production in crabs, to standardise data for the statistical analyses, we used the ratio between egg size and number, respectively, and the average CW of the species. For total egg clutch volume we used the ratio between the square root of the egg mass volume and the CW for each species, due to the allometric relationships between these 2 characteristics (Hines 1982). By means of 3 distinct PERMANOVA (permutational analysis of variance) designs (Anderson 2001), we tested the null hypotheses of: (1) no influence of adult habitat, (2) no influence of larval development characteristics and (3) no differences among different families and, within them, among different adult habitats. In the first 2 cases, two 1-way designs were applied, while, in the third case, a 2-way design, with 'family' as orthogonal and fixed and 'adult habitat' as fixed and nested in family, was applied only to a sub-set of species, belonging to the families most represented in our dataset. Post hoc pair-wise tests were also applied when possible.

Water and air breathing of the embryos of 2 East African crabs. Oxygen uptake rates of embryos of 2 crab species in water and air were measured in the KMFRI Laboratory of Gazi (Kenya). The developmental stage of the embryos was assessed by optic microscope. Ovigerous females carrying eggs at different developmental stages were collected in the field. The truly intertidal, air-breathing mangrove sesarmid Perisesarma samawati was collected from the muddy substratum of the eulitoral Rizophora mucronata belt of the forests where it is active during low tides (Gillikin $\&$ Schubart 2004). The shallow subtidal swimming crab Thalamita crenata was captured in the tidal creeks bordering the mangroves during its maximum peak of activity, nocturnal flood tides (Cannicci et al. 2000). Specimens were brought to the laboratory and maintained in plastic tanks until embryo development was completed. The tanks for both species contained a $5 \mathrm{~cm}$ layer of moist mud with seawater for P. samawati and continuously aerated seawater for T. crenata. A daily turnover of fresh mud and seawater were supplied. $P$. samawati fed on mud, while $T$. crenata was provided with small sesarmid crabs, as prey, every other day. No mortality was recorded during the experiment.

Embryo respiration in water and air was measured on known numbers of eggs carefully separated from the pleopods of ovigerous females and placed in a closed respirometry system. Hamilton microlitre precision syringes (volume: $250 \mu \mathrm{l}$; Hamilton Bonaduz AG), filled with seawater or ambient air, were used as chambers to measure the aquatic and aerial respiration, respectively.

Oxygen saturation was recorded with an oxygen micro-optode sensor (needle-type, fibre-optic microsensor, flat broken tip, diameter: $140 \mu \mathrm{m}$ ) introduced through the top of a Hamilton syringe by a hole in the low-bleed high-temperature septa and connected to a Microx TX2 (PreSens $\mathrm{GmbH}$ ). Prior to insertion, optodes were calibrated with air-equilibrated seawater $(100 \%)$ and with oxygen-free water $(0 \%)$ obtained with a solution of $1 \%$ of sodium sulfite $\left(\mathrm{Na}_{2} \mathrm{SO}_{3}\right)$ in seawater. Oxygen consumption was determined by measuring the decline in oxygen saturation in the known volume of water and/or the air surrounding the eggs in the chamber over a known period of time.

Between 100 and 150 eggs were used for each water respiration test. The eggs were immersed in seawater of between 100 and $200 \mu \mathrm{l}$ in volume for a fixed time of between 20 and $40 \mathrm{~min}$, depending on the different rates of respiration during embryo development. During each measure the syringe was constantly and gently inverted, keeping the eggs continuously moving to avoid clumping. In tests for respiration assays in air, due to the higher concentration of oxygen than in water, we used masses of 200 to 250 eggs, a volume of $60 \mu \mathrm{l}$ and a longer measurement time to obtain a significant decline in oxygen saturation. Recordings were initiated after the berried female had been exposed to ambient air for $60 \mathrm{~min}$. This approach standardised the degree of dryness of the egg. During air respiration tests no attempt was made to stir the syringe, which was immersed in a cylinder filled with water, to avoid accidental ingression of ambient air. Repeated measurements were performed without eggs both in air and water to evaluate possible external factors affecting oxygen consumption. Finally, to obtain the net oxygen uptake of the embryos, values of water oxygen consumption $(13.7 \pm 5.7 \%$ of the experimental consumption rate) were also subtracted. All respiration tests were performed at an average temperature of $30.5 \pm 2{ }^{\circ} \mathrm{C}$.

The embryos involved in the respiration measurements were observed by optic microscope after each test, to assign them to 1 of the 5 developmental stages described in Simoni et al. (unpubl. data) and then stored in $7 \%$ formaldehyde by volume. Images of the embryos stored in Kenya were scanned at a resolution of $3600 \mathrm{dpi}$ and analysed with the software Image $\mathrm{J}$ at the Department of Evolutionary Biology in Florence 
(Italy) to count the experimental eggs and measure their diameter. Changes in the volume of eggs during embryo development in both experimental conditions were indirectly measured by the formula $4 / 3\left(\pi r^{2} R\right)$, where $r$ (minor radius) $=\mathrm{SA}$ (short axis) $/ 2$ and $R$ (major radius) $=$ LA (long axis) $/ 2$.

A full factorial 3-way PERMANOVA was used to test for differences in oxygen uptake, with the factors 'embryo stage', 'respiratory medium' and 'species' all fixed and orthogonal. Post hoc tests were performed when appropriate. All analyses were performed using PRIMER
V6.1 (Clarke \& Gorley 2006) and the PERMANOVA+ for PRIMER routines (Anderson et al. 2008).

\section{RESULTS}

\section{Meta-analyses on egg characteristics}

Our in-depth literature review allowed us to confirm that no relationship is present between egg size and species size, with large species frequently opting for

Table 1. PERMANOVA, examining differences in egg size (egg diameter in $\mu \mathrm{m}$ ), egg number and volume of egg clutch (in mm ${ }^{3}$ ) among crabs with different adult habitats (1-way), with different larval export/retention strategies (1-way) and belonging to different families and with different adult habitats (2-way). M: marine; F: freshwater; IT: intertidal; $\mathrm{T}(\mathrm{M})$ : terrestrial from direct marine ancestors; T(F): terrestrial from direct freshwater ancestors. E: export of larvae in the sea; R: retention of larvae with abbreviated development in specific environments; D: no larval phases, direct hatch of a small crab. For the first 2 PERMANOVAs, post hoc $t$-tests are also shown for significant interactions among factors, while for the 3rd one, significant interactions were too numerous to show; they are discussed in the text. ${ }^{* *} \mathrm{p}<0.01$

\begin{tabular}{|c|c|c|c|c|c|c|}
\hline \multirow[b]{2}{*}{ Adult habitat } & \multicolumn{2}{|c|}{ Egg size } & \multicolumn{2}{|c|}{ Egg number } & \multicolumn{2}{|c|}{ Clutch volume } \\
\hline & & & & & & \\
\hline Source & $\mathrm{df}$ & Pseudo- $F$ & $\mathrm{df}$ & Pseudo- $F$ & $\mathrm{df}$ & Pseudo- $F$ \\
\hline $\begin{array}{l}\text { Adult habitat } \\
\text { Residual } \\
\text { Total }\end{array}$ & $\begin{array}{c}4 \\
97 \\
101\end{array}$ & $21.93^{* *}$ & $\begin{array}{c}4 \\
88 \\
92\end{array}$ & $29.82^{* *}$ & $\begin{array}{c}4 \\
73 \\
77\end{array}$ & 2.1822 \\
\hline \multicolumn{7}{|l|}{ Post hoc $t$-test } \\
\hline $\begin{array}{l}\text { F, T(F) } \\
\text { IT, F } \\
\text { IT, T(F) } \\
\text { M, F } \\
\text { M, IT } \\
\text { M, T(F) } \\
\text { M, T(M) } \\
\text { T(M), F } \\
\text { T(M), IT } \\
\text { T(M), T(F) }\end{array}$ & $\begin{array}{c}0.61 \\
9.78 \\
10.97 \\
5.59 \\
0.55 \\
4.88 \\
0.58 \\
2.19 \\
1.47 \\
2.32\end{array}$ & $\begin{array}{l}0.5543 \\
0.0001 \\
0.0001 \\
0.0001 \\
0.5871 \\
0.0001 \\
0.5640 \\
0.0489 \\
0.1491 \\
0.0405\end{array}$ & $\begin{array}{c}1.58 \\
12.35 \\
14.82 \\
5.00 \\
0.80 \\
5.09 \\
0.68 \\
6.94 \\
0.75 \\
9.90\end{array}$ & $\begin{array}{l}0.1335 \\
0.0001 \\
0.0001 \\
0.0002 \\
0.4277 \\
0.0001 \\
0.4969 \\
0.0002 \\
0.4579 \\
0.0001\end{array}$ & & \\
\hline \multicolumn{7}{|l|}{ Larval export/retention } \\
\hline Source & df & Pseudo- $F$ & $\mathrm{df}$ & Pseudo- $F$ & $\mathrm{df}$ & Pseudo- $F$ \\
\hline $\begin{array}{l}\text { Larval export/retention } \\
\text { Residual } \\
\text { Total }\end{array}$ & $\begin{array}{c}2 \\
100 \\
102\end{array}$ & $65.19^{* *}$ & $\begin{array}{c}2 \\
91 \\
93\end{array}$ & $140.2^{* *}$ & $\begin{array}{c}2 \\
75 \\
77\end{array}$ & 1.66 \\
\hline $\begin{array}{l}\text { Post hoc } \boldsymbol{t} \text {-test } \\
\text { Groups }\end{array}$ & \multicolumn{5}{|c|}{ Post hoc $t$-test } & \\
\hline $\begin{array}{l}\text { E, R } \\
\text { E, D } \\
\text { R, D }\end{array}$ & $\begin{array}{l}8.99 \\
8.66 \\
1.31\end{array}$ & $\begin{array}{l}0.0001 \\
0.0001 \\
0.2144\end{array}$ & $\begin{array}{l}11.58 \\
13.42 \\
1.707\end{array}$ & $\begin{array}{l}0.0001 \\
0.0001 \\
0.1103\end{array}$ & & \\
\hline \multicolumn{7}{|l|}{ Family } \\
\hline Source & $\mathrm{df}$ & Pseudo- $F$ & df & Pseudo- $F$ & $\mathrm{df}$ & Pseudo- $F$ \\
\hline $\begin{array}{l}\text { Family } \\
\text { Adult habitat(Family) } \\
\text { Residual } \\
\text { Total }\end{array}$ & $\begin{array}{c}4 \\
6 \\
55 \\
65\end{array}$ & $\begin{array}{l}15.11^{* *} \\
16.79^{* *}\end{array}$ & $\begin{array}{c}6 \\
6 \\
62 \\
74\end{array}$ & $\begin{array}{l}30.72^{* *} \\
18.27^{* *}\end{array}$ & $\begin{array}{c}5 \\
5 \\
45 \\
55\end{array}$ & $\begin{array}{l}1.62 \\
1.31\end{array}$ \\
\hline
\end{tabular}



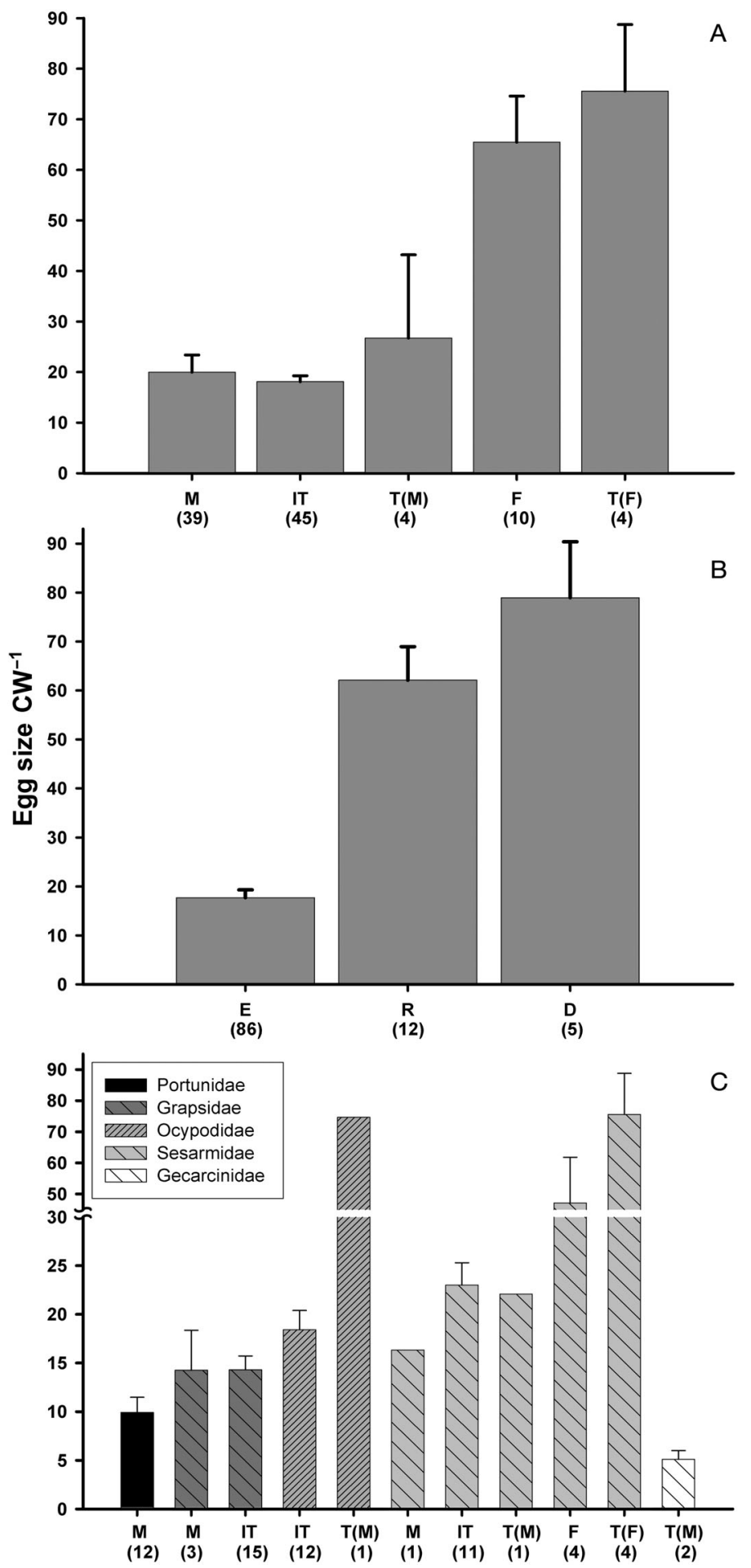

Fig. 1. Trends in egg size of bachyuran crabs based on published data. Ratio between the average egg size (diameter; in $\mu \mathrm{m}$ ) and the average carapace width (CW; in $\mathrm{mm}$ ) of crabs grouped on the basis of $(\mathrm{A})$ the life-style of the adults, (B) their larval retention strategy and (C) within their families and the life-style of the adults. M: marine; F: freshwater; IT: intertidal; $T(M)$ : terrestrial from direct marine ancestors; $T(F)$ : terrestrial from direct freshwater ancestors; E: export of larvae in the sea; R: retention of larvae with abbreviated development in specific environments; D: no larval phases, direct hatch of a small crab small eggs (Table S1 in the supplement at www.intres.com/articles/suppl/m430p121_supp.pdf).

The habitat of adults influenced egg size (Table 1, Fig. 1A), with freshwater crabs and terrestrial species from freshwater ancestors bearing eggs not dissimilar to each other, but significantly larger than marine, intertidal and terrestrial species from direct marine ancestors (Table 1, Fig. 1A). On the other hand, no significant differences in egg size emerged among these latter categories. Also the type of larval development appears to be significantly related to egg size (Table 1, Fig. 1B). Species that evolved an export strategy of larvae produce smaller eggs than both those with larval retention and those with direct development, which display eggs of similar size. Significant differences in egg size were found among the 7 most well-represented families, but also among species with different ecological characteristics within the families (Table 1, Fig. 1C), confirming that the habitat of adults strongly influences egg size, across families. The post hoc pair-wise tests showed significant differences between the families characterised by freshwater-related species and all others. Potamonidae had significantly larger eggs than all other species, while no differences were found between families that only included marine species, such as the Portunidae and Majidae, and those including mainly intertidal, such as the Grapsidae, and truly terrestrial species from marine ancestors, such as the Gecarcinidae.

The results of the analyses on egg numbers produced per single clutch were perfectly comparable to the above-mentioned results on egg size. Freshwater and freshwater-related species showed a significantly lower number of eggs per clutch with respect to the species whose adults colonise marine and intertidal habitats, as well as to the terrestrial species with marine origins (Table 1, Fig. 2A). The large-egg species that evolved larval retention and direct development strategies produced less eggs than the crabs characterised by an export strategy of larvae with full development (Table 1, Fig. 2B), confirming an evolutionary trade-off between egg number and size. As for the egg size, we found differences in egg number produced per clutch both at the family level and within the various families, when species colonising different habitats were present (Table 1, Fig. 2C), confirming the influence of this factor on the response variable.

The volume of the egg mass produced by the various species analysed, on the other hand, showed no relationship with the habitat chosen by the adults, with the strategy of retention/dispersion of larvae, or with the phylogenetic relationships among species (Table 1, Fig. 3). The volume of the clutch was only related with the average $\mathrm{CW}$ of the species. 

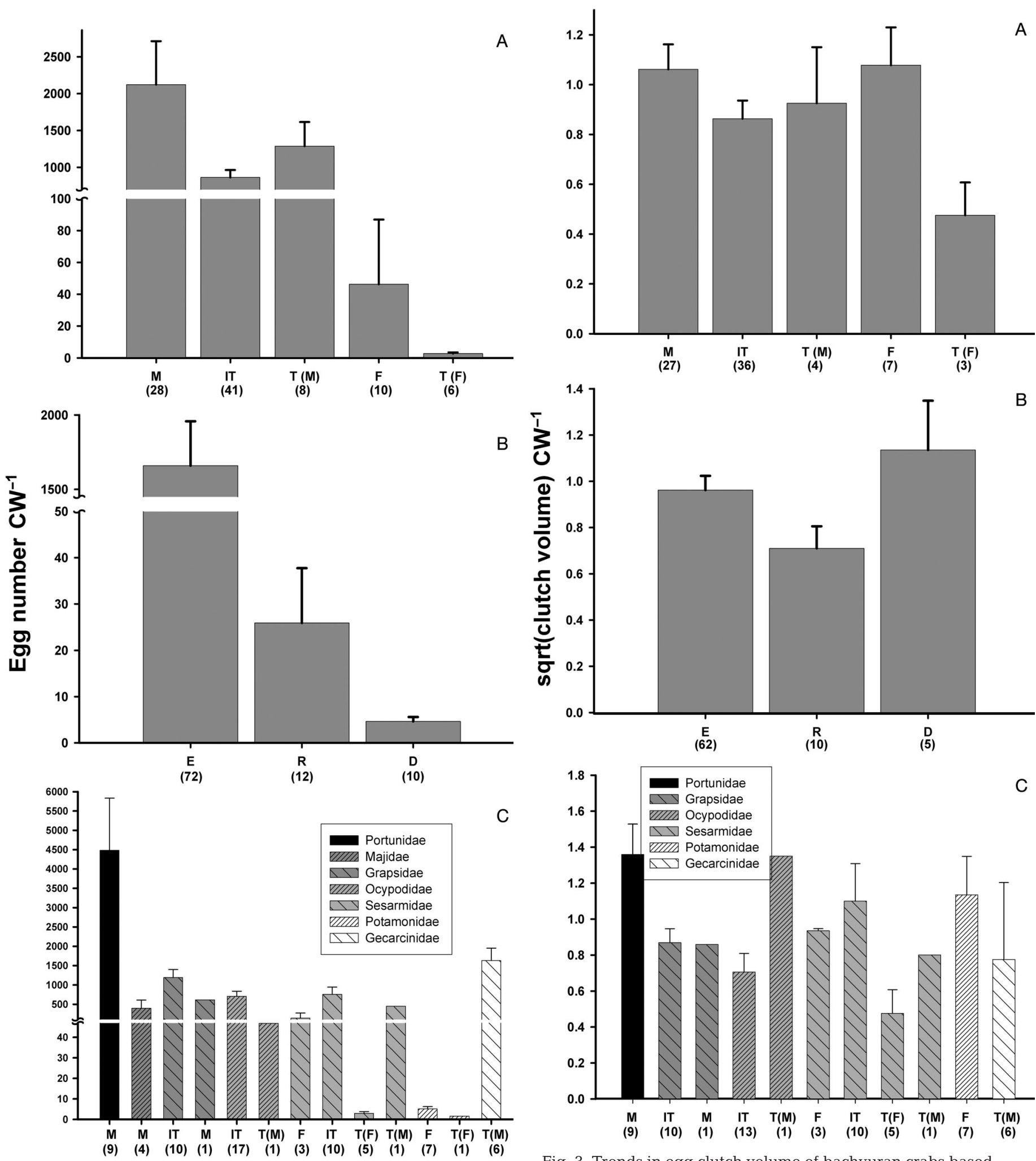

Fig. 2. Trends in egg number produced by bachyuran crabs based on published data. Ratio between the average egg number and the average carapace width $\left(\mathrm{CW}_{\text {; }}\right.$ in $\mathrm{mm}$ ) of crabs grouped on the basis of (A) the life-style of the adults, (B) their larval retention strategy and $(C)$ within their families and the life-style of the adults. For abbreviations see Fig. 1

Fig. 3. Trends in egg clutch volume of bachyuran crabs based on published data. Ratio between the square root of the average volume of the egg clutch $\left(\mathrm{mm}^{3}\right)$ and the average carapace width (CW; in $\mathrm{mm}$ ) of crabs grouped on the basis of $(\mathrm{A})$ the life-style of the adults, (B) their larval retention strategy and (C) within their families and the life-style of the adults. For abbreviations see Fig. 1 


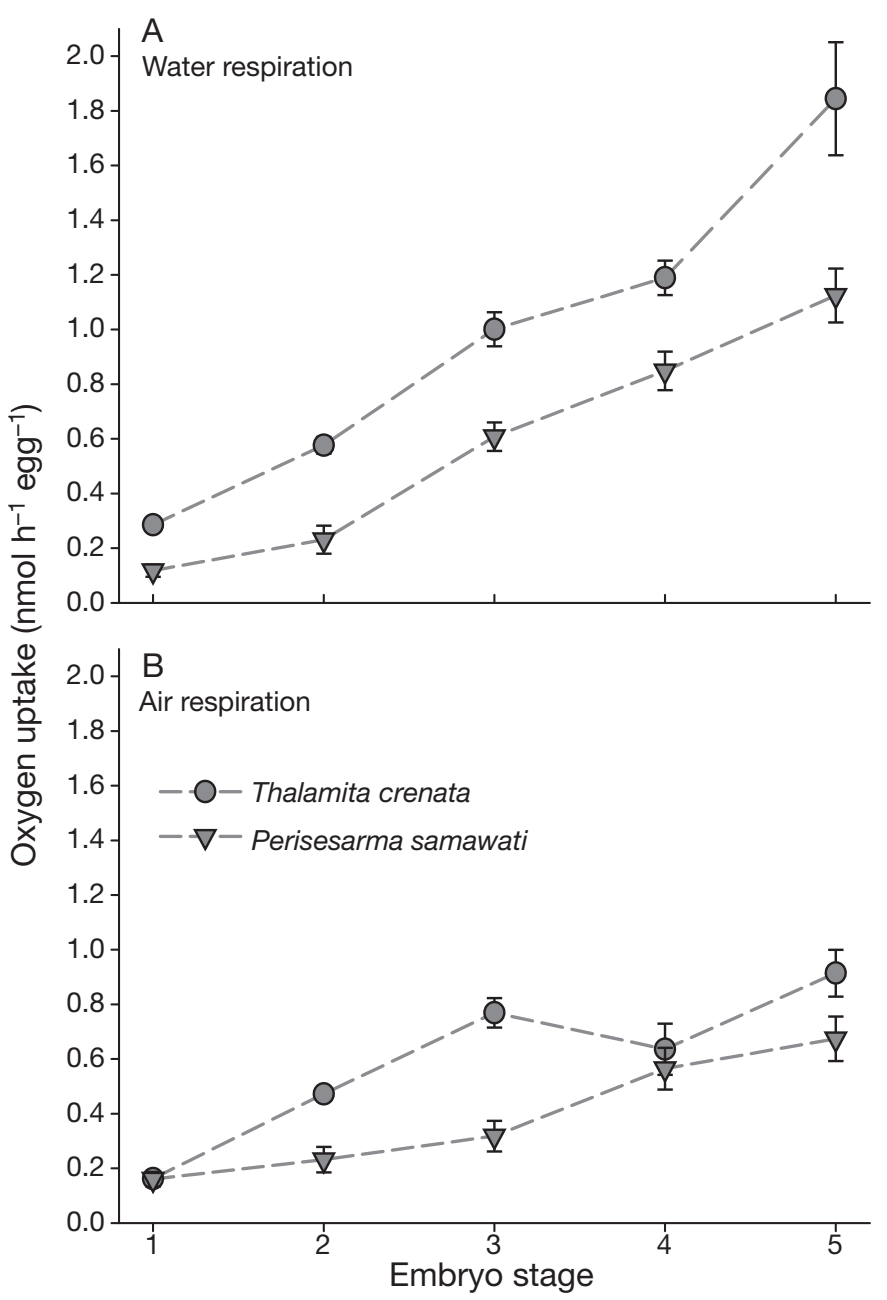

Fig. 4. Thalamita crenata, Perisesarma samawati. Oxygen uptake of embryos. (A) Water and (B) air respiration rates by embryo stage $(\mathrm{n}=6$ to $10, \pm \mathrm{SE}$; when the error bar is not visible, error is within the symbol size)

Table 2. Thalamita crenata, Perisesarma samawati. PERMANOVA examining differences in respiration rate of embryos at different stages and in different respiratory media. Post hoc $t$-tests are also shown for significant interaction among factors

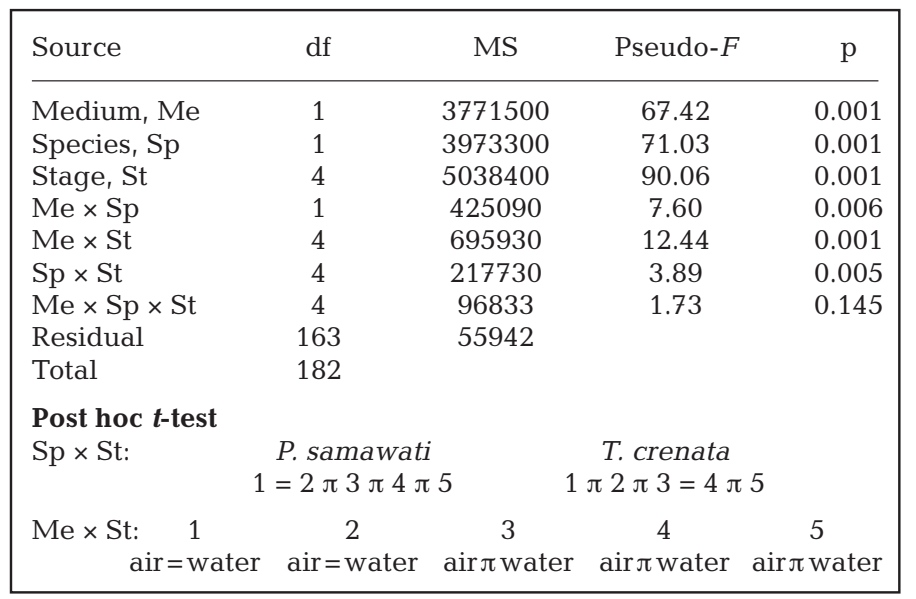

\section{Water and air breathing of the embryos of 2 East African crabs}

The embryos of the intertidal Sesarmidae Perisesarma samawati and of the swimming crab Thalamita crenata were shown to be able to take up oxygen from both air and water (Fig. 4). Aquatic and aerial respirations show a typical exponential increase during ontogenesis in both species. PERMANOVA confirmed that the progressive development of embryonic complexity was paralleled by both higher oxygen consumption and higher metabolic rate, except in the first 2 stages of $P$. samawati, which showed similar respiration rates, and in the third and fourth embryonic stages of $T$. crenata, mostly due to a drop in oxygen uptake in air by the developing embryos (Table 2, Fig. 4). Oxygen uptake in air, for almost all embryonic stages, resulted in a 2-fold lower rate with respect to water, while $T$. crenata embryos showed a higher oxygen uptake than those of $P$. samawati, regardless of the medium (Table 2).

\section{DISCUSSION}

Which external forces can select for the morphology of eggs and reproductive output in terrestrial brachyurans? As for any other aquatic organism, the major physical challenges, as discussed by Martin \& Strathmann (1999), are desiccation, UV radiation, large temperature variability and reduction of mechanical support. In brachyurans, these challenges are mainly endured by berried females, who give mechanical support to and control the micro-environment of embryos until larval hatching. Crabs, in fact, adopt highly effective parental care, and the evolution of egg-carrying forms established a strong link between mother and offspring. This egg-carrying phase has significant consequences for the life style and activity regime of the berried intertidal and terrestrial females. Most brooding females of the terrestrial and semi-terrestrial Ocypodidae of the genus Uca and Ocypode, for instance, are known to rarely leave their burrows, where they can control and limit embryo desiccation and avoid exposure to both ultraviolet radiation and high temperatures (reviews in Crane 1975, Wolcott 1988). On the other extreme, the well known migrations performed by Gecarcoidea natalis of Christmas Island serve a 2-fold purpose, since copulation occurs only at the end of the seaward journey (Adamczewska \& Morris 2001). Migration is thus undertaken both to brood the egg masses in burrows on the coast, i.e. in a more marine and less stressful habitat, and to hatch the larvae in the sea. 
Another selective force for reproductive traits is surely oxygen availability for embryos, both in marine and terrestrial environments. Few studies have addressed the quantification of the oxygen uptake and metabolism of developing embryos in marine crustaceans. These studies have established the central role of oxygen in shaping various life-history traits, such as egg and clutch size, development duration, hatching success and larval quality. Embryo development is accomplished through an exponential increase in oxygen consumption, which occurs to maintain an efficient metabolism for the increasing complexity of the organism during ontogenesis (Taylor \& Leelapiyanart 2001). Small differences in oxygen uptake are present during the first stages of development, whereby single or a few undifferentiated cells gain oxygen by simple diffusion through the chorion. In contrast, major differences in oxygen uptake rates between developmental stages have been observed at higher levels of organization, due to the development of a complete circulatory system and the differentiation of organs and tissues (Taylor \& Leelapiyanart 2001). At later stages, simple diffusion appears insufficient to provide the required amount of oxygen, and an active water intake occurs in combination with the development of efficient osmoregulatory processes and the onset of heart beating (Spicer \& Morritt 1996, Reiber \& Harper 2001, Taylor \& Seneviratna 2005, Seneviratna \& Taylor 2006).

Fluctuations of oxygen availability are also dependant on the size of the embryo mass and the relative position of the eggs. The oxygen level is rapidly depleted in the centre of the clutch, with respect to the external layers, although a series of parental care actions are provided to maintain elevated water refurbishment and circulation. Adjustments in embryonic metabolic rates also occur independently of the surrounding oxygen availability and appear to be stage dependant, with a higher plasticity of oxygen consumption evident with progression in development (Naylor et al. 2001, Baeza \& Fernández 2002).

Given the strong importance of oxygen availability, the traits of eggs and egg masses of terrestrial and semi-terrestrial species were supposed to be shaped by anoxia, due to the hypothesised, although never tested, low oxygen tension within the egg masses exposed to air. However, our analyses proved that both evolutionary trends hypothesised for egg size and egg mass dimension by Strathmann \& Hess (1999) and Hartnoll et al. (2007), respectively, are not supported by an extensive dataset on crab reproductive features. In fact, no dimensional trend related to eggs along the terrestrialisation evolutionary pathways could be gleaned from published data, since the eggs of terrestrial species are not larger than those of their marine relatives. The eggs of freshwater-related species in- deed proved to be larger than those of the marinerelated and terrestrial ones, but this could be explained by evolution towards a shortened larval phase, ranging from a reduced number of larval stages to the direct hatching of young crabs (Bliss 1968, Anger 1995). Although differences in egg size could be detected among families, these could be ascribed to the homogeneity of habitat preferences among species belonging to the same family, a common feature in crabs. The Portunidae and Majidae species we could analyse, for instance, were all marine, while Gecarcinidae and Potamonidae were all truly terrestrial and freshwater related, respectively. More interesting findings were achieved in families, such as the Grapsidae, Ocypodidae and Sesarmidae, in which group species belonging to different habitats. In these cases, we found intrafamily differences in egg size, which support the strong link between egg size, freshwater environment and the larval retention strategy. The data available from literature, in summary, strongly suggest that egg size is mainly related to the characteristics and fate of larvae and not to the level of terrestrialisation of the adult.

Accordingly, the number of eggs produced per clutch is strongly related to larval dispersion/retention strategies, showing that crabs have to face the evolutionary trade-off existing between the dimension of single eggs and the number of eggs produced per reproductive event, as highlighted by Hines (1982). Thus, the dependences of egg number from adult habitat and developmental strategy mirrored the ones discussed for egg size, with freshwater-related and directdevelopment strategy species producing significantly less eggs than all other categories. As a result, the overall energy allocated to a single spawning event, expressed as total clutch volume, was not influenced by any ecological or evolutionary factor, but by allometric constraints alone (Hines 1982). Thus, published data do not support the hypothesis that terrestrial crabs may reduce their reproductive effort per single event (Hartnoll et al. 2007), showing that average clutch volume is similar among marine, freshwater and terrestrial species.

We suggest that the above-mentioned hypotheses fail to explain the actual trends found in nature for 2 reasons. The first is that the authors underestimated the capability of air breathing of crab embryos, thus basing their theories on the assumption that the egg masses should occupy water-based micro-environments and, consequently, overestimating the levels of anoxia within the interstices. The second reason is the influence of the terrestrial environment on maternal care.

The leading benefit for evolving a terrestrial development is the 30-fold abundance and 10000 times higher diffusiveness of oxygen in air than in water. 
Thus, the opportunity to adopt aerial respiration could indeed reduce the problems described for marine species due to the limiting oxygen demand within masses of developing embryos (Strathmann \& Hess 1999). Our novel results on embryonic respiration in the semiterrestrial Perisesarma samawati and in the shallow subtidal Thalamita crenata support the hypothesis of true bimodal respiration in the early life stages of brachyurans, even in species still strongly related to the sea. The embryos of the 2 East African crabs proved, in fact, to uptake oxygen from both media, with $T$. crenata showing an overall higher oxygen demand than $P$. samawati. Since the eggs of the 2 species are similar in dimension, this difference can only be ascribed to differences in the overall metabolic rates of the 2 species, an issue which should be addressed in further studies. Our data also highlighted an important evolutionary trend towards air-breathing embryos, since the comparison of intertidal and shallow subtidal species revealed the failure of fully efficient oxygen uptake in air for the latter. Embryos of $T$. crenata, in fact, develop completely in water, with a few sporadic emersions during low tides. While their oxygen uptake in water increases through all developmental stages, they cannot maintain successful respiration in the air, showing the water dependence of the ontogenetic stages.

These novel data confirmed the results of a recent study on an amphibious Jamaican sesarmid, Armases miersii, by Simoni et al. (unpubl. data) and show, for all 3 species, that oxygen uptake in air, for almost all embryonic stages, results in a 2-fold lower rate with respect to water. Simoni et al. (unpubl. data) interpreted this interesting result in 2 contrasting ways. The first hypothesis is that the embryos are not completely able to extract enough oxygen from the air to complete full development out of the water. Consequently, they would respond to the lack of oxygen diffusion at a tissue level with a correspondent decrease in metabolic rate, by means, for instance, of bradycardia. On the other hand, the low oxygen uptake in air could be the direct consequence of the lower metabolic cost of extracting oxygen from air than from water. Thus, water respiration implies an active and expensive process, in terms of energy, to maintain normoxia within the eggs (Simoni et al. unpubl. data).

Regarding the influence of the terrestrial environment on maternal behaviours, it seems that, compared to water, the higher availability of oxygen in the air reduces the energetic costs of maternal care to maintain a normoxic condition within the egg mass. A crucial energetic cost of parental care in marine crabs is oxygen provision to the clutch through active ventilation or water circulation (Fernández et al. 2000). Early studies addressed the importance of oxygen availability to embryos and the consequent behaviour of ovigerous females (Wheatly 1981, Naylor et al. 1997, 2001). These works, which principally focus on the requirements of the embryo, describe the maternal behaviour of Carcinus maenas and Cancer pagurus and reveal an active control of the egg mass milieu independent of environmental conditions. An increased oxygen demand, due to temperature variation or local hypoxia, is rapidly supplied through the intensification of abdominal flapping and providing efficient ventilation. On the other hand, a series of studies by Miriam Fernández and colleagues have investigated parental care in terms of oxygen provision to the egg mass, focusing on the role of the mother (Fernández et al. 2000, 2002, 2003, 2006, Baeza \& Fernández 2002, RuizTagle et al. 2002, Brante et al. 2003, Fernandez \& Brante 2003). These studies have noted the high metabolic expenditure associated with active and continuous parental care. Brooding females perform a series of behaviours such as abdomen flapping and pleopod beating that frequently intensify with embryo development. These behaviours have important consequences for the adult, in terms of both egg losses and oxygen consumption, used as proxies for mechanical and energetic costs, respectively. At the interspecific level, the energetic investment of berried females appears to be size dependent. While larger species undergo higher metabolic expenditure, smaller species do not show increased metabolic demand, even if brooding behaviours are present. However, the direct benefits of parental care appear evident when the oxygen/water exchange is evaluated inside the egg mass. These studies demonstrated a clear difference in oxygen concentrations at the periphery of the mass with respect to the centre. On-line and continuous measurements of oxygen availability have shown the effectiveness of water exchange by abdominal flapping. This behavioural strategy increases hatching success through 2 mechanisms: the ability to lay larger egg masses than those laid by non-ventilating mothers and the synchronization of development time between the embryos at the centre of the mass and those laid at the periphery.

Although bimodal respiration of crab embryos seems a common feature, including in shallow-water species, it does not imply a real independence from water of the egg clutches. In the only available study on the water dependence of embryos of the amphibious crab Armases miersii the authors found that, even if embryos could breathe in air throughout their development, the eggs of water-limited females could not produce healthy larvae (Simoni et al. unpubl. data). These results led the authors to suggest that other important physiological pathways could be limited if water cannot be provided to the embryos, such as, for instance, excretion and osmoregulation processes. Unfortunately, 
nothing is known about the excretion of crab embryos, although they are thought to rely on ammonia just like both the larvae and adults (Greenaway 1999, Weihrauch et al. 2004). In particular, no data are yet available on the ontogeny of osmoregulation or on excretory patterns in terrestrial crabs, although Charmantier \& Charmantier-Daures (2001) pointed out that 'a wider knowledge of osmoprotection and osmoregulation of embryos may also lead to renewed insight on adaptation to terrestrial conditions, particularly in [...] decapods'. Due to this huge gap in our knowledge, the effects of these physiological traits on the water dependence of embryos are, at present, difficult to ascertain. Simoni et al. (unpubl. data) found that air-breathing embryos of $A$. miersii experimentally deprived of water could not develop normally, resulting in an elevated number of misbehaving, dead and morphologically deformed larvae at hatch. The authors suggested that abnormal embryo development could be caused by their nitrogen excretion mechanisms, supposedly still strongly water dependent, although they cautioned that further studies must be carried out to corroborate this supposition.

In conclusion, amphibious and shallow-water crabs have bimodal embryos capable of oxygen uptake from both water and air, as demonstrated in recently published studies and by the novel data presented here. This evolutionary step towards land completely changes our understanding of the reproductive biology of land crabs and, in particular, the brooding strategies and parental care of their females. Indeed, existing hypotheses regarding the evolutionary trends in egg morphology, reproductive output and egg mass characteristics of terrestrial crabs should be rethought in light of the ability of their embryos to breathe in air throughout their development. However, amphibious crab embryos did not prove to be totally independent of water; they are still vulnerable to the stressing factors peculiar to emergent habitats. Thus, the behaviour and parental care performed by brooding mothers remain extremely important in providing a vital microhabitat in which embryo development can occur.

The current state of the field, outlined here, is a fascinating starting point for future ontogenetic approaches to the study of terrestrial adaptations in crabs. Since the scant available data come from subtidal and intertidal species, an increase in our knowledge of the respiratory traits of embryos in truly terrestrial crabs is probably the first step to take in order to ascertain whether the trend toward full air breathing in embryos is consistent. A further step would be to extend the ontogenetic approach to other physiological processes taking place during embryo development. Greater understanding of processes such as osmoregulation and nitrogen excretion is, in our opinion, needed to assess the degree of water dependence of embryos and eggs. In parallel with the physiological analyses of embryos, new hypotheses on the evolutionary trends shaping parenting behaviour and the characteristics of maternal care in land environments should be tested to develop a more complete evolutionary scenario of the ongoing terrestrial invasion of crabs.

Acknowledgements. We are very grateful to Roger and Helen Hughes for their invitation to join the symposium held to celebrate Roger's retirement and thank all the co-organisers who made the event such a success. We are indebted to Sara Fratini and Carlotta Mazzoldi for critical discussion of the first draft of the manuscript. Thanks also to Stefania De Vanna and Daniele Spigoli for their help with field and laboratory work. S.C. and R.S. were funded by the University of Florence and by M.I.U.R. (Ministero Italiano dell'Università e della Ricerca Scientifica, ex60\%). F.G. was funded by the Marie Curie Individual Fellowship (IEF) Number FP7.

\section{LITERATURE CITED}

Adamczewska AM, Morris S (2001) Ecology and behavior of Gecarcoidea natalis, the Christmas Island red crab, during the annual breeding migration. Biol Bull 200:305-320

Anderson MJ (2001) A new method for non-parametric multivariate analysis of variance. Austral Ecol 26:32-46

Anderson MJ, Gorley RN, Clarke KR (2008) PERMANOVA+ for PRIMER: guide to software and statistical methods. PRIMER-E Ltd, Plymouth

Anger K (1995) The conquest of freshwater and land by marine crabs: adaptations in life-history patterns and larval bioenergetics. J Exp Mar Biol Ecol 193:119-145

> Baeza JA, Fernández M (2002) Active brood care in Cancer setosus (Crustacea: Decapoda): the relationship between female behaviour, embryo oxygen consumption and the cost of brooding. Funct Ecol 16:241-251

Bartholomew GA (1987) Interspecific comparison as a tool for ecological physiologists. In: Feder ME, Bennett $\mathrm{AF}$, Burggren WW, Huey RB (eds) New directions in ecological physiology. Cambridge University Press, Cambridge, p 11-37

Bliss DE (1968) Transition from water to land in decapod crustaceans. Integr Comp Biol 8:355-392

Brante A, Fernández M, Eckerle L, Mark F, Pörtner HO, Arntz W (2003) Reproductive investment in the crab Cancer setosus along a latitudinal cline: egg production, embryo losses and embryo ventilation. Mar Ecol Prog Ser 251:221-232

Burggren WW (1992) The importance of an ontogenetic perspective in physiological studies. Amphibian cardiology as a case study. In: Wood SC, Weber RE, Hargens AR, Millard RW (eds) Physiological adaptations in vertebrates: respiration, circulation and metabolism. Marcel Dekker, New York, NY, p 235-253

Burggren WW, McMahon BR (1988) Biology of the land crabs. Cambridge University Press, Cambridge

Cannicci S, Ruwa RK, Ritossa S, Vannini M (1996) Branchfidelity in the tree crab Sesarma leptosoma (Decapoda, Grapsidae). J Zool (Lond) 238:795-801

> Cannicci S, Barelli C, Vannini M (2000) Homing in the swimming crab Thalamita crenata: a mechanism based on underwater landmark memory. Anim Behav 60:203-210

Charmantier G, Charmantier-Daures M (2001) Ontogeny of osmoregulation in crustaceans: the embryonic Phase 1. Am Zool 41:1078-1089 
Charmantier G, Wolcott DL (2001) Introduction to the symposium: ontogenetic strategies of invertebrates in aquatic environments. Am Zool 41:1053-1056

Clarke KR, Gorley RN (2006) PRIMER V6: user manual/tutorial. PRIMER-E Ltd, Plymouth

Crane J (1975) Fiddler crabs of the world. Ocypodidae: genus Uca. Princeton University Press, Princeton, NJ

Diesel R (1992) Maternal-care in the bromeliad crab, Metopaulias depressus - protection of larvae from predation by damselfly nymphs. Anim Behav 43:803-812

Diesel R, Horst D (1995) Breeding in a snail shell—ecology and biology of the Jamaican montane crab Sesarma jarvisi (Decapoda, Grapsidae). J Crustac Biol 15:179-195

Farrelly CA, Greenaway P (1993) Land crabs with smooth lungs: Grapsidae, Gecarcinidae, and Sundathelphusidae ultrastructure and vasculature. J Morphol 215:245-260

Farrelly C, Greenaway P (1994) Gas exchange through the lungs and gills in air-breathing crabs. J Exp Biol 187: $113-130$

Fernandez M, Brante A (2003) Brood care in brachyuran crabs: the effect of oxygen provision on reproductive costs. Rev Chil Hist Nat 76:157-168

Fernández M, Bock C, Pörtner HO (2000) The cost of being a caring mother: the ignored factor in the reproduction of marine invertebrates. Ecol Lett 3:487-494

Fernández M, Pardo LM, Baeza JA (2002) Patterns of oxygen supply in embryo masses of brachyuran crabs throughout development: the effect of oxygen availability and chemical cues in determining female brooding behavior. Mar Ecol Prog Ser 245:181-190

Fernández M, Ruiz-Tagle N, Cifuentes S, Pörtner HO, Arntz W (2003) Oxygen-dependent asynchrony of embryonic development in embryo masses of brachyuran crabs. Mar Biol 142:559-565

Fernández M, Calderón R, Cifuentes M, Pappalardo P (2006) Brooding behaviour and cost of brooding in small body size brachyuran crabs. Mar Ecol Prog Ser 309:213-220

Fratini S, Vannini M, Cannicci S, Schubart CD (2005) Treeclimbing mangrove crabs: a case of convergent evolution. Evol Ecol Res 7:219-233

Gillikin DP, Schubart CD (2004) Ecology and systematics of mangrove crabs of the genus Perisesarma (Crustacea: Brachyura: Sesarmidae) from East Africa. Zool J Linn Soc 141:435-445

Greenaway P (1999) Physiological diversity and the colonization of land. In: Schram FR, Klein JCVV (eds) Crustaceans and the biodiversity crisis, Vol 1. Koninklijke Brill NV, Leiden, p 823-842

Hartnoll RG (1988) Evolution, systematics, and geographical distribution. In: Burggren WW, McMahon BR (eds) Biology of the land crabs. Cambridge University Press, Cambridge, p 6-54

Hartnoll RG, Baine MSP, Britton A, Grandas Y, James J, Velasco A, Richmond MG (2007) Reproduction of the black, land crab, Gecarcinus ruricola, in the San Andres Archipelago, western Caribbean. J Crustac Biol 27:425-436

Hines AH (1982) Allometric constraints and variables of reproductive effort in brachyuran crabs. Mar Biol 69:309-320

Innes AJ, Taylor EW (1986) The evolution of air-breathing in crustaceans: a functional analysis of branchial, cutaneous and pulmonary gas exchange. Comp Biochem Physiol A 85:621-637

Martin KLM, Strathmann R (1999) Aquatic organisms, terrestrial eggs: early development at the water's edge. Introduction to the symposium. Am Zool 39:215-217

Morris S (2001) Neuroendocrine regulation of osmoregulation and the evolution of air-breathing in decapod crustaceans. J Exp Biol 204:979-989

> Morris S (2002) The ecophysiology of air-breathing in crabs with special reference to Gecarcoidea natalis. Comp Biochem Physiol B 131:559-570

Naylor JK, Taylor EW, Bennett DB (1997) The oxygen uptake of ovigerous edible crabs (Cancer pagurus) (L.) and their eggs. Mar Freshw Behav Physiol 30:29-44

Naylor JK, Taylor EW, Bennett DB (1999) Oxygen uptake of developing eggs of Cancer pagurus (Crustacea: Decapoda: Cancridae) and consequent behaviour of the ovigerous females. J Mar Biol Assoc UK 79:305-315

> Reiber CL, Harper SL (2001) Perspectives on cardiac physiological ontogeny in crustaceans. Zoology 104:103-113

> Ruiz-Tagle N, Fernández M, Pörtner HO (2002) Full time mothers: daily rhythms in brooding and nonbrooding behaviors of brachyuran crabs. J Exp Mar Biol Ecol 276:31-47

Seneviratna D, Taylor HH (2006) Ontogeny of osmoregulation in embryos of intertidal crabs (Hemigrapsus sexdentatus and H. crenulatus, Grapsidae, Brachyura): putative involvement of the embryonic dorsal organ. J Exp Biol 209:1487-1501

Spicer J, Morritt D (1996) Ontogenic changes in cardiac function in crustaceans. Comp Biochem Physiol A 114:81-89

> Strathmann RR, Chaffee C (1984) Constraints on egg masses. 2. Effect of spacing, size, and number of eggs on ventilation of masses of embryos in jelly, adherent groups or thin-walled capsules. J Exp Mar Biol Ecol 84:85-93

Strathmann RR, Hess HC (1999) Two designs of marine egg masses and their divergent consequences for oxygen supply and desiccation in air. Am Zool 39:253-260

> Taylor HH, Leelapiyanart N (2001) Oxygen uptake by embryos and ovigerous females of two intertidal crabs, Heterozius rotundifrons (Belliidae) and Cyclograpsus lavauxi (Grapsidae): scaling and the metabolic costs of reproduction. J Exp Biol 204:1083-1097

Taylor HH, Seneviratna D (2005) Ontogeny of salinity tolerance and hyper-osmoregulation by embryos of the intertidal crabs Hemigrapsus edwardsii and Hemigrapsus crenulatus (Decapoda, Grapsidae): survival of acute hyposaline exposure. Comp Biochem Physiol A 140:495-505

Vannini M, Oluoch A, Ruwa RK (1997) The tree-climbing crabs of Kenyan mangroves. In: Kjerfve B, De Lacerda BL, Diop ES (eds) Mangrove ecosystems studies in Latin America and Africa. UNESCO, New York, NY, p 325-338

Warner GF (1967) The life history of the tree crab Aratus pisoni. J Zool 153:320-335

Weihrauch D, Morris S, Towle DW (2004) Ammonia excretion in aquatic and terrestrial crabs. J Exp Biol 207:4491-4504

Wheatly MG (1981) The provision of oxygen to developing eggs by female shore crabs (Carcinus maenas). J Mar Biol Assoc UK 61:117-128

Wolcott TG (1988) Ecology. In: Burggren WW, McMahon BR (eds) Biology of the land crabs. Cambridge University Press, Cambridge, p 55-96 